\title{
VAK: Protecting High Standards in Science
}

On the role played by the High Attestation Commission of the Russian Federation (VAK) of Russia in managing domestic science, criteria, and professional selection, as well as the role the of scientific periodicals in this process; Acta Naturae talked to the president of this commission, academician Mikhail Kirpichnikov of the Russian Academy of Sciences.

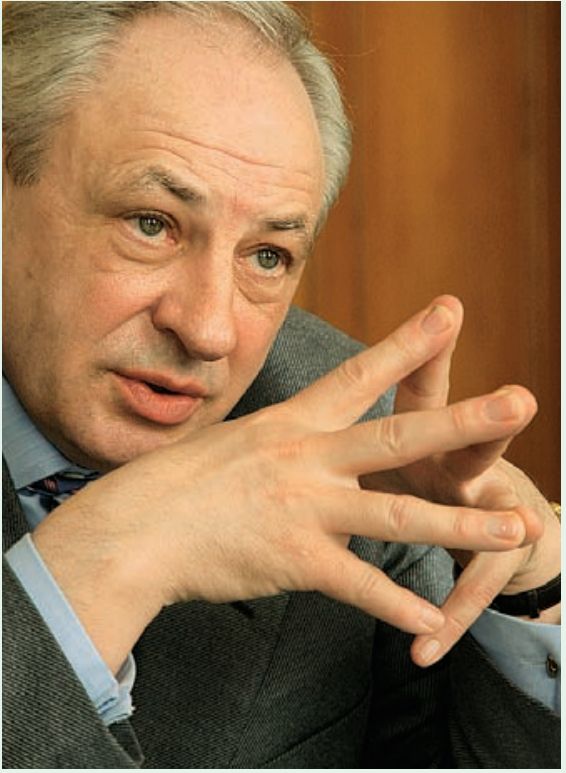

Mikhail Kirpichnikov: "we do not subdivide journals into bad and good ones; we subdivide journals into those can be used for expertise and those cannot." I consider it essential to estimate the quality level, especially when speaking about an outstanding specialists, by formal quotation and the impact-factor of the journal where his or her articles are published. However, a non-formalized estimation is important as well. Thus, I stand for balance between formal requirements and a normal expert system. It ought to be noted that the expertise level and points will change with time. But a definite number of points will remain beyond formalization. That is the major problem.

It is widely believed that Russian authors are often discredited against in international periodicals: i.e., they are rarely referenced to due to their Russian affiliation. Do you agree with this opinion?

I have similar views on this problem. I think that discrimination exists. I don't know if it's significant, but I am sure it is present. In my opinion, the factor of having lived in a closed society played a negative role in that situation. When our society became open (I avoid the word "economics," because "society" is a wider term), pressure was removed. However, this process is 
slow, it may take years.... For the time being, the "closed-society" mentality remains.

\section{ANALYSIS OF RUSSIAN SCIENTIFIC PERIODICALS}

Where do you consider the difference to be between the quality of Russian science and the quality of science management, including the regulation of the appraisal system of higher scientific qualification for the personnel controlling the quality of scientific periodicals?

Indeed, Russian science has some problems, as does the appraisal system of higher scientific qualification personnel, by which I mean the High Attestation Commission of the Russian Federation (VAK). What role do scientific periodicals play in the appraisal system? I emphasize, not for me as a scientist, but for the appraisal system? How do we try to use it? First of all, as an external expert. Moreover, a priori we are at liberty to choose the rules of ordering external experts, and being among these external VAK experts is not a special indicator for a journal. If the results of VAK performance are useful for scientific periodicals, we'll be very glad. As often happens in science, an unintended result can be as useful as the achievement of the stated goal. There are many examples: the creation of a collider led to the invention of the Internet. What is more important now? They are at least comparable. However, when construction began at the European Organization for Nuclear Research, nobody planned to create the World Wide Web, this much is certain. My position is as follows: I don't want the problems of the appraisal system to be confused with the problems of Russian scientific periodicals.

Not long ago, you took part in a conference titled Scientific Periodicals in Russia: Topical Issues and Developmental Prospects in Present-Day Conditions, which was held at the Moscow Polytechnical Museum. What is your assessment of the conference's results?

First, I must note that we were not the initiators of that conference, but when we learned about it, we joined with enthusiasm, because it was a use- ful event. In any case, we planned to gather editors and publishers to discuss our prospects. In this context I am fully satisfied with the conference's results. Actually, the conference organizers set a more important and more relevant mission: to discuss the problems of Russian scientific periodicals. I'm talking not as the president of VAK, but as a representative of the commonwealth of scientists. My speech at the conference was devoted to that very question of separating the problems of scientific periodicals from external expertise related to the VAK List.

\section{THE VAK LIST OF JOURNALS IS A TEMPORARY MEASURE}

What place is given to the so-called VAK List (the list of Russian and foreign journals where the results of scientific investigations are to be published for defending a thesis) in this aspect of science?

We regard the VAK List as an element of the existing scientific attestation system. The attestation begins with an applicant. Then it involves a reviewer; leading organization; thesis council; then the VAK Expert Council; and, finally, VAK proper. All of this is the attestation system that should come to mind when you pronounce the word VAK. I am deeply convinced that the main problem in the attestation system that remains relevant to this day is the catastrophic decline in the level of theses written in the 1990s and the early 2000s. It was not just this decline, but "loss of genre," as I usually call it. By this I mean that, according to the original and current rules, thesis work is meant for educational research attestation; this is scientific qualifying work, not the draft laws often offered today or projects of certain instructions. However, I by no means diminish the importance of this activity. A draft law enacted may be more important than thousands of theses, but it is another genre. There are many different methods to increase the theses quality level. Some of these methods are within the framework of the attestation system considered. In my opinion, the thesis council is the most "complicated," yet most efficient, component of this system. Alterations at this level may lead to significant changes in the system proper. External expertise is another way to that quality. One problem with external expertise is that of scientific periodicals, and it is only one of several important problems. Currently, patents, as an element of external expertise, are legal, and I think this was a great achievement. Patents are as important as publications for thesis defense in engineering sciences. In their turn, monographs are of prime importance for humanities and social sciences. I mean serious reviewed monographs.

Hence, today the VAK system needs the same external collective expertise as scientific periodicals. This problem appeared a long time ago, and we were not the first who started discussing it. As early as 2001-2002, our predecessors offered the first draft of the VAK List. However, as often happens in Russia, the documents existed as a normative basis rarely taken into account even by their creators. Until 2005, the VAK List was discussed rather rarely, and it attracted attention only after it began to be applied. Then, finally, people felt that it was a matter of great significance.

I understood from the very beginning that it was essential to get off the VAK List, as such, and since the end of 2006 I have publicly discussed that problem. It cannot be emphasized enough that this measure is absolutely compulsory and temporary. As was mentioned above, this problem arose due to the decline in the theses' quality and the violation of the "purity" of that genre. As a consequence, we finally escaped the "cursed heritage of the past" (appeals from the doctorate theses of 1999-2000 defended without a single publication) only by the end of 2007 . Several kinds of reports, conference theses, and so forth were offered as publications. Eventually, the good idea of involving external expertise was offered. However, external expertise was rarely used, but that is a secondary problem. From the mid-1990s to 2006, theses defense was characterized by exponential growth rates (almost 15\% a year) and it was only in 2006 that an end was put to the chaos.

Let's get back to the List. The rules for getting onto the VAK List were assumed to be made maximally transparent so that the choice of the jour- 


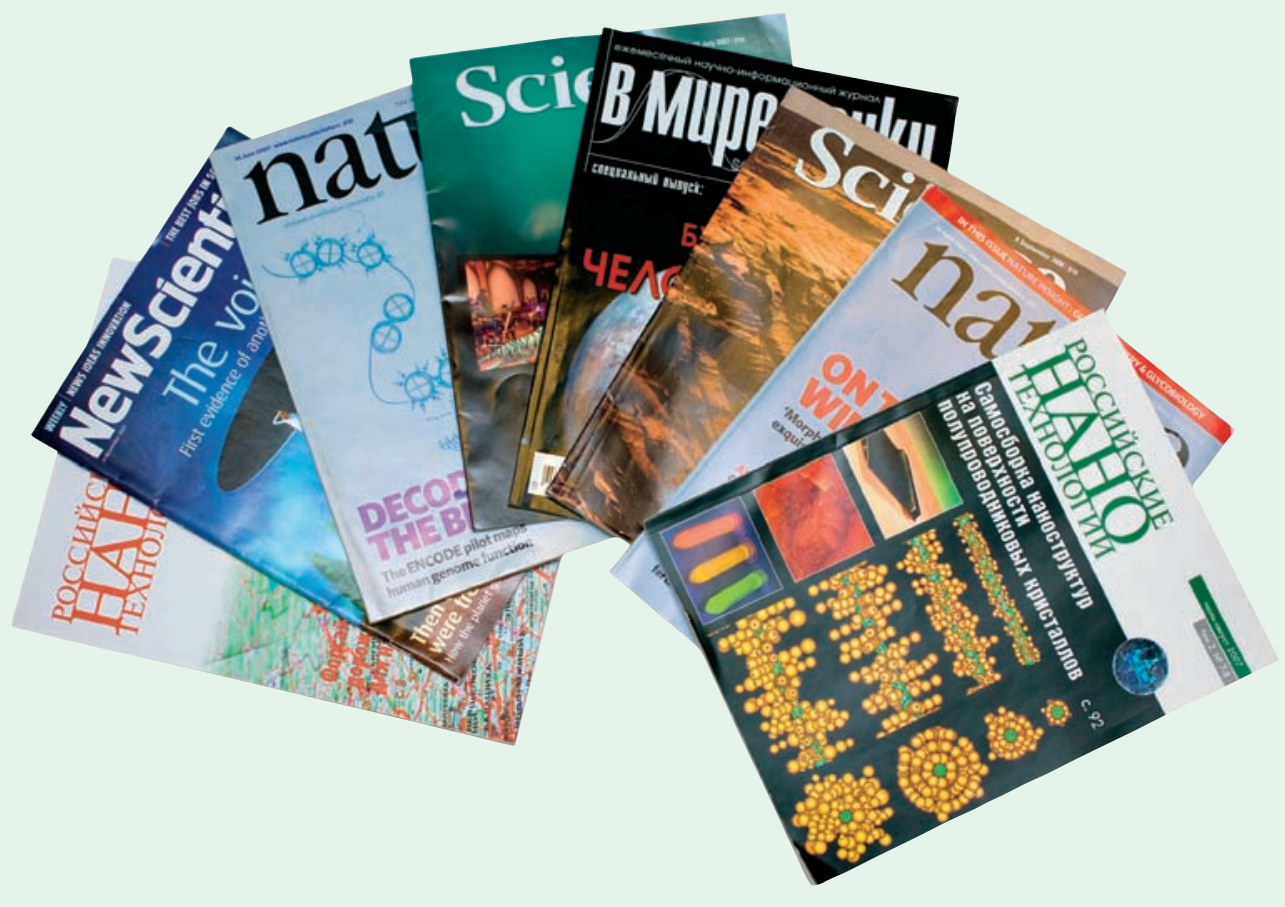

nals would depend neither on the VAK President, nor on VAK (minimally, at least), nor on expert councils. The primary task of VAK, the VAK President, and the experts is to offer requirements. As soon as the requirements are written, it is essential to meet these requirements in order to get on the VAK List.

Initially, those rules were observed.... Did we succeed? I don't think so. However, from the very beginning it was clear that it was a temporary measure, and later on we planned to get off the special VAK List and proceed to public databases. This goal has been declared, manifested, and presented on the VAK site since 2008.

Will the VAK List be replaced with a Public online Database?

How do you envision future VAK policy concerning the question under discussion?

It is important that we are the first, and, in contrast to our previous activity, we are going to be offering this kind of VAK policy for the List for five years. Today, the presence of journals in the public international bases of scientific periodicals, such as Web of Science and Scopus (this list may be extended with time), is sufficient enough to be included in the VAK List. If a journal falls to the above-mentioned databases, it automatically rates as a compulsory publication in the VAK List. It will be the same for Russian journals. Today, this requirement is too stringent for them (only 200-300 journals meet this requirement). And we are still carrying out attestation in Russia, which is why we offer the five year transition period.

What do you mean by "stringent"? The quality of articles or the publishing business?

I don't want to discuss the publishing business, because it can sidetrack the question under discussion. I guess ing authorities. As for us, we adopted some amendments to our requirements at the recent VAK conference and are planning to publish them. Moreover, the requirements to be published will be valid for five years. These requirements take into account many of the proposals offered at the conference in the Polytechnical Museum, and they will be valid for five years. However, if we see any changes in Russian journals, the requirements will change as well.

As for the journals, initially they were not happy because they didn't that is a problem for the correspond- want to change anything. After collective serious discussions, we found that they were not ready for change. For instance, the journals could not afford online full-text versions. We removed that requirement. Previously, the journal issue should have been followed by the issue of its online version. Now there has to be an online version issued by subscription or it has to be free after one year. Thus, all claims concerning the commercial problems of the publishers and all questions related to their opposition to that deal were settled. If you want, you get one additional year, if you don't, I return to my first declaration. We represent VAK and thus are entitled to choose the experts who will meet our requirements. If you don't like something, nobody forces you. I have already said at the conference and can repeat now that we do not subdivide the journals into bad and good ones; we subdivide the journals into those that can be used for expertise and those that cannot. You must admit that it would be absurd to compare Playboy with Nature.

Actually, you control only one instrument: the List. You cannot close it, can you?

No, I cannot. I know what is behind this considerable interest in the problem of journals, but it is a drop in the ocean compared to attestation. For us this drop is one of numerous expertise instruments, but it can incidentally relieve scientific periodicals of journals that are not reviewed or poorly reviewed. In spring of 2006, the government submitted in its decree a claim to have at least one compulsory publication in the journal from the VAK List for thesis defense. At the same time, compulsory publications of doctorate and Ph.D. theses abstracts on the Internet became obligatory as well. Today, these requirements are being fulfilled and it matters a good deal. That measure did not cause violent indignation: all went down well from the very beginning of its introduction. Which is why this measure is unavoidable. We are proceeding to move in this direction, though it is rather difficult due to poor financial and technical support. I think that security systems with online access will appear in the course of 
time, and it will be possible to get past the security system and ask an applicant any question online.

In principle, the list is a disputable and temporary thing; it is really an administrative measure. Today it is the only real method that can have an effect on the current situation.

Today, if you want your article to be published in certain journals, including good ones, you have to pay...

It is common practice. However, it is important to know the publication rules of a particular journal beforehand. A journal should publish rules for the authors. This is one of the new requirements. If a journal states that one page costs one ruble, then it shouldn't cost one thousand rubles. The difference appears due to "under the table" calculations, "black market," etc. And I speak out against this very practice. There is a range of authoritative international paid journals; it is a common practice. Another problem, likely related to the realities of our country, is the requirement for all journals wishing to be in the VAK List to institute free publication for graduate students. This requirement included in the new criteria often gives rise to criticism. Clearly, this requirement is not perfect, but there are no perfect solutions. What should we do with an article written by a graduate student with six doctors of science as co-authors?

In 2006-2007, many complaints such as "they take money" were heard. But give me at least one address where the rules are being violated. The only thing $\mathrm{VAK}$ can do is to remove a journal from the VAK List. But no applications demanding this have been submitted yet. You see, it is difficult to solve this problem without a special document. On the other hand, it is clear that authors are apprehensive about their fates.

You have data on all candidates and doctors of science. How deep is this database?

I would say that it exists and is in order. In general, intensive use of ITtechnologies is one of the most important directions of our work. For instance, we are ready for a storm of protests which are likely to arise if we offer to publish full-text versions of theses online.

On the other hand, if we wish to be united with the whole civilized world, we are obliged to turn to online publishing. However, taking into consideration the fact that this whole system of passwords and so forth will barely work in Russia (technically it is quite possible, but mentally it is not), I accept the position of the publishers that was declared at the conference at the Polytechnical Museum. With time I think we'll manage to put this measure into execution as well.

One more important thing. We are going to fight for the equality of online publications included on our list. And this is a rather complicated task. Sometimes it is difficult to explain that an online journal is as good as a printed one. In the past, it was difficult enough just to explain the necessity of online publication of theses abstracts. It is essential to convince people that the publications will no longer be stolen.

PURCHASE, SALE, AND THEFT OF THESES Does VAK have any computerized system for fighting plagiarism?

We have the Antiplagiat system, which was launched and advertised in a big way. This system exists today, but due to financial and technical problems it operates in the pilot regime. Few terminals have access to this program. I guess that in a country as big as Russia the Antiplagiat system is doomed to operate in the pilot regime, because about 30,000 theses will scarcely be subject to check by this program. However, it has proven to be effective several times.

I think it is essential to come to a kind of solution that may be comparable to a stoplight. It is obvious that many people do not observe traffic rules, some of them run a red light, but most people do stop because they know that they may be caught, penalized, etc. Thus, the fact and declaration that we use the Antiplagiat program is more important than the capture of one or two unprincipled authors and public punishment.

Nevertheless, public responsibility is quite a useful measure. This measure concerns all the attestation stages (from applicant through opponents and public councils); i.e., everyone is responsible for their actions, and if somebody violates the rules, his or her reputation can suffer significantly. However, public responsibility has some disadvantages. Declarations in the presence of the mass media can lead to court proceedings, because people caught red-handed tend to be fearless and are of the conviction that those who shout louder are right. This situation causes a lot of problems. The commission consists of only 45 people who have to withstand this pressure.

But the problem appears to be political; many officiaries, deputies, and businessmen are eager to defend theses in the sphere of economics, sociology, and management, discrediting the system of scientific attestation. They wish to become academicians, doctors of science, and so forth, having written the thesis New Information about Management in the Middle of Nowhere.

In regards to the problem of bought theses, it is rather difficult to calculate their percentage in the total number of theses defended, but I do not think it is high. Nevertheless, it does happen. I don't often travel by subway, but once I had to and heard people discussing the places where defending one's thesis was cheaper. It is disgusting. The moral consequences may be really disastrous. I realize how much such facts damage scientific prestige. But in similar cases I always make reference to the entropy increase law, which acts in both nature and in the social sphere, everywhere. The first provision of this law is as follows: if you do nothing, chaos will grow; if you want to create order, you will have to deploy great effort.

\section{BAD GRADUATE STUDENTS AND BAD THESES}

Is the low quality of theses prepared for defense related to the low quality of postgraduate education?

Unfortunately, today, according to the normative basis, VAK is responsible only for the attestation of highly qualified personnel. Preparing highly qualified personnel does not fall with- 
in VAK's duties. Moreover, VAK can by no means influence this situation. I often bring up this question. This is a great gap in the normative basis, and we must solve this problem somehow. The situation is as follows: organizations that have few candidates open postgraduate schools and send someone to ask VAK to approve the opening of a thesis council. Thus, postgraduate students appear without the participation of VAK and ask for VAK's expertise only to open a thesis council.

Comparing the postgraduate schools of 1996, which had 60,000 students, to those of 2006-2007, which had 150,000 students, we observe a three increase fold in the number of postgraduate students. It is clear that no attestation system, strict or not, can work properly in these conditions. Moreover, colossal external pressure exists, we try to fight against it, but it is rather hard because it is objective. Almost half of all postgraduate positions are given to social and humanitarian sciences, while only $5 \%$ of scientists carry out investigations in this sphere. This situation reflects on the attestation system. About $50 \%$ of theses defended belong to these spheres. As a result, we see a theater of the absurd. However, this picture does not reflect the interests of society and the state.

It turns out that VAK has minimum authority in this situation, correct?

We have no authority at all in preparing graduate students. As for postgraduate studies, I quite agree with Bauman Institute Rector Igor Borisovich Fedorov: postgraduate studies in the sphere of technical and natural sciences must extend over at least four years, or we'll have profanation. I think that the Ministry of Science and Education shares my opinion, but the force of inertia is too great.

\section{ATTESTATION SYSTEM IN THE FUTURE What is the difference between de-} fending a PhD and a doctorate thesis?

The doctorate thesis to be defended is examined by the VAK expert council. The $\mathrm{PhD}$ thesis is considered to be defended as per the decision of only the thesis council, which is why
PhD theses cause more problems. To confirm this decision, the $\mathrm{PhD}$ thesis is directed to VAK, and the expert council studies it selectively. There are exceptions when a person who does not work in the scientific or educational sphere plans to defend a thesis. These authors, by decision of the Presidium, are called by the Expert Council to check their qualification. Hence, the PhD thesis becomes an object of VAK expert council attention under exceptional circumstances. This brings about the following question: do we need VAK or not?

In the future, the personal attestations of both $\mathrm{PhD}$ students and doctors of science will be entrusted, not completely, but to a large extent, to universities and strong scientific organizations. Today, conditions are unfavorable for achieving this idea.

First it is necessary to create a system of our own Cambridges, Oxfords, and MITs with the same type of authority and image consciousness, and then plan the creation of a new normative basis. We'll need many years to do this. However, if we remove this barrier, soon we'll have not 30,000 but 300,000 theses a year. That's what we'll get. I guarantee it will happen immediately. That is our psychology.

Moreover, it must be kept in mind that the system of social support is related directly to scientific degrees.

Finally, one more idea is related to the attestation system and its development in the future. I don't know when we'll be ready to entrust the attestation to certain institutions of higher education, especially in spheres where the participation of the state must be significant: medicine, science, education, and national safety.

Does this mean that the state must not participate in the attestation at all, as many carelessly claim? No, I think that only personal attestation must be eliminated from the state functions. However, our state, like all civilized countries, is obliged to attest those thesis councils which carry out attestation and regulate their level. Such authorities are present in every country.

Will those who were attested under softer conditions be subject to reattestation?
No, I think that a law cannot be retroactive. As I understand it, you are asking if it will be unfair to those who will defend the theses in tougher conditions? If we have admitted the mistake of "lowering the bar" (I think everybody has admitted it), we should correct it.

You see, the main problem is the competitiveness of our cadres. There can be tragic consequences, as platitude produces platitude. But this is a question of scientific prestige!

I'll tell you my opinion about the attestation system of the academic and teaching staff: in spite of all the disadvantages of VAK, I am sure it is the best expert system in Russia, the most developed and advanced. It can be used as a model for creating public state expertise concerning all the most important questions. We pretty much have only one such example. VAK is a dual system, consisting of state and civil institutions made up of scientific and scholastic corporations combined with academies, communities, rector unions, etc. It makes sense.

Cooperation within this system is rather complicated, and we understand that. For instance, why does the expert system, which works in the West, barely work in Russia? There are two major reasons. First, free expertises have never been good, and VAK has not received any money for ten years. Now we get financial support but cannot obtain confirmation on how to spend it.

The second cornerstone, which serves as a basis for expertise, is public responsibility. Experts should know that if they make a mistake, they will be outcasts in their communities. The issue is not about corruption, which is spoken about much more often than necessary; the plain truth is that Russia is known for so-called "nepotism" in a wide sense of the word. For instance, Ivan Ivanovich does not demand money from Ivan Petrovich, because he has known him for 30 years and simply cannot refuse.... There is only one method to fight against nepotism. When I became VAK president, the first thing I offered was the replacement of $40 \%$ of the expert council. I did so not because people were stealing, but because I believe that no one can be a member of the expert 
council for 30 years; you become a link in the chain, even if you don't wish to. The expert system must be subject to rotation; no one can be a member of the expert system for ever.

The next stage is the thesis councils. I am sure it is the largest component of the attestation system. In 2006 , we called off all the one-time councils. What was a one-time council? A very important person in a big car arrived at VAK and, using administrative and occasionally monetary resources, forced the creation of a council. In recent years, no similar council has been created. The network of reserve councils (about a thousand) was liquidated. Actually, there were some good councils. All good councils of the reserve network were transferred into the main network. That was the first stage of work aimed at optimizing the thesis councils. In 2007-2008, we carried out complete reattestation of the councils. Today all rearrangements have been completed, and the system has achieved a dynamic balance. The number of closed councils is similar to that of opened councils. In early 2006, a little over four thousand thesis councils existed. Today only three thousand are working.

Is it necessary to introduce special levels of scientific qualification for managers (economists)?

I think something is necessary, but not scientific qualification. Let's leave aside for a minute different kinds of impostors. We are talking about (a) honest, (b) ambitious, and (c) brilliant specialists in their sphere. They wish to be attested by society and by the state. The same situation is characteristic of scientific and educational attestation. We can either try to fight affectedly against this situation, inevitably creating niches for corruption, or take the road of "horizontal conformity." Today we have a system of scientific and educational attestation represented by the existing VAK. Administrators, practicing lawyers, and businessmen must get a chance to receive a corresponding status. It is possible to do this within the frame- work of the current attestation system. However, the rules of the game will change, and new experts will be needed. People will get a chance to defend theses within the framework of this state and public attestation system. This system is not entirely analogous to the "magister/doctor of business administration" system, but they have some similar features. We'll be able to tell to these honest and ambitious people that a doctor of economic sciences is no better or worse that a doctor of business administration. The same rule works for a doctor of business administration: he is no better (or worse!) than a doctor of physical and mathematical sciences. Thus, it is essential to travel the road of "horizontal conformity." How will this situation work out? First of all, I'll repeat again: the social order must be satisfied. I consider it senseless to fight this situation. This is just one idea. I would like to talk about it. How will the situation work out then? These measures will surly reduce the pressure on the "boiler of scientific and educational attestation." On the other hand, our governors, politicians, and businessmen still want to be "great" scientists rather than "great" administrators (there are some objections to that).

As a matter of fact, the state can set a standard and declare that it will accept people for work in the organs of state administration who have a Masters of Business Administration degree (for instance).

\section{"OLD" AND "NEW" SCIENCES}

Is it necessary to change the classification of scientific qualifications due to the appearance of "new" sciences which study phenomena at the junction of "old" sciences? What is VAK's attitude towards this question? And what should people working at the interdisciplinary level do?

The last time scientific qualifications were reconsidered was when I was a minister. In 2006, I as VAK president wrote a letter to Andrei Alexandrovich Fursenko, where I offered to reconsider the qualifications. Science does not stand still, it constantly de- velops. Moreover, according to normative documents, this procedure shall be carried out every five years. I did it consciously in order to explain that was not the responsibility of VAK, but of the Ministry of Science and Education. This is a problem of scientific and technical policy. Scientific and technical programs and so forth, as well as qualifications for defense (and, accordingly, the thesis councils), should be shaped on the basis of scientific qualifications. It is essential to raise the issue of the correspondence of scientific and higher educational qualifications, which has never been done. This is more relevant than comparing non-conformity between our qualifications and Western qualifications. Now the ministry has all the required authority, and, thus, a unique chance to solve all the problems. Hence, scientific qualifications are not a problem of VAK, but of the state's scientific and technical policy. VAK is a consumer of this system as are the institutions of higher education.

Now I'll express my own attitude to the situation under discussion. Honestly, nature knows nothing about physics, chemistry, or biology. It simply exists as a unique phenomenon. Then, human beings, thanks to the peculiarities of their mentality, started constructing models that led to the appearance of biology, chemistry and then to objective consequences. Absolutely objective physical, chemical, and biological methods appeared. But nature knows nothing about it! That is why, in my opinion, the most interesting things appear on the boundaries between the sciences. Even if we carry out more delicate subdivisions into biophysics, biochemistry, bioorganics, and molecular biology, the most interesting things will still happen not "under the lamp," but at the junctions. Everything happens there. I see no contradictions therein. It is impossible to build a model "for all times." The models must change. Our ideas about the sciences must change in accordance with the development of the natural science. I think this is relevant for society as well. Though, for sure, that is a subject for aspecial discussion. 